\title{
RESSIGNIFICAR A FORMAÇÃO DOCENTE NA RELAÇÃO COM AS EXPERIÊNCIAS VIVIDAS
}

\author{
Cyntia Simioni França (UNICAMP)* \\ https://orcid.org/0000-0002-1812-3696 \\ Nara Rubia Carvalho Cunha (UNICAMP)** \\ https://orcid.org/0000-0003-1807-3825 \\ Guilherme do Val Toledo Prado (UNICAMP)*** \\ https://orcid.org/0000-0002-2415-8369
}

\section{RESUMO}

O texto apresenta duas pesquisas desenvolvidas em nível de doutorado, tematizando a relação entre a produção de conhecimentos históricoeducacionais e experiências vividas, que se desdobraram em pesquisas-ação de formação continuada, compostas por professores de Educação Básica, lotados em escolas públicas das cidades de Londrina (PR) e Ouro Preto (MG). Nesse país, a partir de 1990, em relação com a esfera mundial, vem prevalecendo uma formação docente fundada na urgência do capitalismo e em modelos utilitaristas. Problematizamos tais modelos que desvalorizam os saberes plurais e não reconhecem os professores como produtores de conhecimento. Com vistas a resistir ao avanço da modernidade tardia, buscamos construir com os professores projetos formativos dissonantes das tendências prevalecentes na lógica global do capital. Investimos numa metodologia composta por movimentos reflexivos dinamizados por rememoração coletiva, produção e partilha de narrativas de cunho biográfico e intersubjetivo.

Palavras-chave: Formação docente. Produção de conhecimento histórico e educacional. Memórias.

\section{ABSTRACT}

\section{REFRAME TEACHER TRAINING IN RELATION TO LIVED EXPERIENCES}

The text presents two studies developed at the doctoral, studying the relationship between the production of historical-educational knowledge and lived

\footnotetext{
Doutora em Educação pela Universidade Estadual de Campinas (UNICAMP). Docente do Programa de Mestrado em História Pública (PPGHP/UNESPAR) e do Programa de Mestrado Profissional em Ensino de História da Universidade Estadual do Paraná (ProfHistória/UNESPAR). Membro do Grupo de Estudos e Pesquisas em Educação Continuada (GEPEC/UNICAMP) e Kairós: Educação das Sensibilidades, História e Memória (UNICAMP). E-mail: cyntiasimioni@yahoo.com.br

** Doutora em Educação pela Universidade Estadual de Campinas (UNICAMP). Docente do Departamento de História da Universidade Federal de Uberlândia (UFU). Membro do Grupo de Estudos e Pesquisas em Educação Continuada (GEPEC/ UNICAMP) e Kairós: Educação das Sensibilidades, História e Memória (UNICAMP). E-mail: nrcdois@yahoo.com.br

*** Doutor em Linguística Aplicada pela Universidade Estadual de Campinas (UNICAMP). Docente do Programa de Mestrado em Educação da Universidade Estadual de Campinas (UNICAMP). Coordenador do Grupo de Estudos e Pesquisas em Educação Continuada (GEPEC/UNICAMP). E-mail: vptoledo@gmail.com
} 
experiences, which became research-action training, composed of teachers from Basic Education at public schools in the cities of Londrina (PR) and Ouro Preto (MG). In this country, since 1990, in relation to the world, a teacher education based on the urgency of capitalism and utilitarian models has prevailed. We problematize models that devalue plural knowledge and do not recognize teachers as producers of knowledge. Seeking to resist the advance of late modernity, we seek to construct with the teachers formative projects dissonant from the prevailing capital logic. We invested in a methodology composed of reflexive movements dynamized by practices of collective remuneration, production and sharing of biographical and intersubjective narratives.

Keywords: Teacher education. Production of historical and educational knowledge. Memories.

\section{RESUMEN}

\section{RENUNCIAR LA FORMACIÓN DOCENTE EN RELACIÓN CON LAS EXPERIENCIAS VIVAS}

El texto presenta dos investigaciones desarrolladas a nivel de doctorado, centradas en la relación entre la producción de conocimiento histórico-educativo y las experiencias vividas, que se desarrollaron en investigaciones de acción de educación continua, compuestas por maestros de Educación Básica, con sede en escuelas públicas de las ciudades. Londrina (PR) y Ouro Preto (MG). En ese país, desde 1990, en relación con la esfera mundial, ha prevalecido una formación docente basada en la urgencia del capitalismo y en modelos utilitarios. Problematizamos tales modelos que devalúan el conocimiento plural y no reconocen a los maestros como productores de conocimiento. Con el fin de resistir el avance de la modernidad tardía, buscamos construir proyectos formativos con maestros que sean inconsistentes con las tendencias prevalecientes en la lógica global del capital. Invertimos en una metodología compuesta por movimientos reflexivos simplificados por el recuerdo colectivo, la producción y el intercambio de narraciones biográficas e intersubjetivas.

Palabras clave: Formación del profesorado. Producción de conocimiento histórico y educativo. Recuerdos.

\section{Introdução}

Este artigo é um recorte temático de duas pesquisas desenvolvidas dentro do Programa de Pós-Graduação em Educação da Universidade Estadual de Campinas (Unicamp), junto ao Grupo de Estudos e Pesquisas em Educação Continuada (GEPEC) do Programa de Pós-Graduação da Faculdade de Educação da Unicamp, e em diálogo com o grupo de pesquisa Kairós: educação das sensibilidades, história e memórias, vinculado ao Centro de Memória dessa mesma universidade.
A pesquisa O Canto da Odisseia e as Narrativas Docentes: dois mundos que dialogam na produção de conhecimento histórico educacional (FRANÇA, 2015) foi desenvolvida de 2012 a 2015, enquanto a Primaveras Compartilhadas: (re)significando a docência na relação com cidade, memórias e linguagens (CUNHA, 2016) se desenvolveu de 2012 a 2016. Ambas foram orientadas pela professora Dra. Maria Carolina Bovério Galzerani e pelo professor Dr. Guilhereme do Val Toledo Prado e tiveram 
como mote principal de investigação a relação entre formação docente e experiências vividas, assumindo a investigação narrativa, potencializada pela rememoração coletiva, como meio de produção de conhecimento crítico e reflexivo sobre a docência. As duas pesquisas foram protagonizadas por professores de Educação Básica, lotados em escolas públicas em cidades do interior do Brasil: Londrina, no Paraná, e Ouro Preto, em Minas Gerais.

O GEPEC, grupo de pesquisa onde se desenvolveram as duas teses de doutorado, foi criado em 1996 e suas investigações têm se destacado no meio acadêmico e escolar por serem protagonizadas por professores e demais profissionais da educação que investigam sua própria prática em seus ambientes de trabalho, ou seja, suas pesquisas não são sobre professores e educadores, mas deles ou com eles. Do mesmo modo, tais pesquisas não são sobre o ambiente escolar, são na escola, da escola, com a escola. 0 Grupo tem sido espaço privilegiado para produção conjunta, na parceria entre escola e universidade, de conhecimentos e saberes ligados ao universo da educação e da docência. Seu projeto de formação é fundamentado em uma epistemologia transgressora, subsidiada em reflexões produzidas por profissionais da educação nos contextos de suas práticas (GERALDI; FIORENTINI; PEREIRA, 1998).

Entre os caminhos metodológicos comumente empregados pelos pesquisadores estão as pesquisas narrativas, com diferentes abordagens (LIMA, 2015; PRADO, 2014; PRADO et al., 2015) e, geralmente, articulada a essas últimas, a pesquisa-ação (ELLIOT, 1998; FRANCO, 2005). 0 psicólogo Lev Vygostsky, os filósofos Mikhail Bakhtin e Walter Benjamin, e o filósofo e educador Paulo Freire compõem os principais referenciais teórico-metodológicos.

O grupo de pesquisa Kairós, com o qual dialogamos durante todo o desenvolvimento das duas teses de doutorado, tem uma trajetória de investigação que antecede sua configuração como grupo de pesquisas junto ao Conselho Nacional de Desenvolvimento Científico e
Tecnológico (CNPq), órgão responsável pelo incentivo à pesquisa no Brasil. Sua origem remete a pesquisas realizadas e orientadas pela professora Dra. Maria Carolina Bovério Galzerani sobre temas variados, mas tendo como problemática central a investigação dos processos de educação política dos sentidos e o trabalho com as memórias como base para a produção de conhecimentos históricos e educacionais. 0 referencial teórico-metodológico é composto, sobretudo, pelo filósofo Walter Benjamin e pelos historiadores Edward Palmer Thompson e Peter Gay.

No diálogo com o grupo de pesquisa Kairós, a discussão sobre educação política dos sentidos foi articulada a essas pesquisas de formação docente, que assumiram as práticas formativas como expressão de uma cultura moderna capitalista, ou seja, de uma experiência histórica alargada, na qual se destaca a agência humana no emaranhado de conflitos e resistências.

A educação política dos sentidos ou das sensibilidades (ou apenas educação das sensibilidades) pode ser definida, resumidamente, como um processo amplo de educação que atravessa as dimensões sensíveis e racionais dos seres humanos e que é construído de forma coletiva em meio a tensões (BENJAMIN, 1994; GAY, 1988; THOMPSON, 1998).

Nas pesquisas realizadas pelo grupo de pesquisa Kairós, a educação política das sensibilidades não se refere a uma educação para o sensível ou para o estético, nem mesmo a uma investigação que tome as sensibilidades tão somente como objeto de pesquisa no campo da história. Tendo em vista uma concepção de cultura que é ao mesmo tempo instituída por e instituidora de aspectos sociais, políticos e econômicos da sociedade (BENJAMIN, 2006), a constituição das sensibilidades é lida numa perspectiva histórica, cultural e educacional, tanto porque se admite que elas sejam construções ancoradas no tempo e no espaço, quanto porque se percebe que seu engendramento é histórico, social e subjetivo, ou seja, as sensibi- 
lidades não são nem naturais nem estritamente impositivas, mas reformulações contínuas, ligadas ao encontro dos sujeitos com o mundo, numa afetação mútua que vai moldando as experiências individuais, conforme assinala o historiador Peter Gay (1988, p. 19), visto que "as experiências comprovam pois a existência de um tráfego ininterrupto entre o que o mundo impõe e o que a mente exige, recebe e reformula".

No que tange à formação docente, tanto o grupo de pesquisa GEPEC quanto o Kairós têm se configurado como locus de resistência a modelos formativos alicerçados na racionalidade instrumental e no crescente tecnicismo na educação. Ao assumir os professores como protagonistas de suas práticas e das investigações sobre as mesmas (GERALDI; FIORENTINI; PEREIRA, 1998) e ao incentivar a compreensão da historicidade das relações que engendram a docência e o trabalho educativo, esses grupos buscam romper com processos formativos que desconsideram os professores como sujeitos produtores de conhecimento e que a eles se impõem desconsiderando suas experiências singulares (GALZERANI, 2004).

No Brasil, há muito é percebido o predomínio de práticas de formação de professores pautadas na racionalidade instrumental, caracterizadas por cursos no modelo treinamento ou capacitação para desenvolvimento de competências, geralmente que atendem às exigências do mercado de trabalho em escala industrial. Essa vertente implica em uma formação de tecnólogos que executam tarefas, mas não necessariamente conhecem os fundamentos do seu trabalho. Assim, a formação se limita a um saber prático desvinculado do contexto social, cultural, econômico e político.

Os cursos de formação como treinamento contribuem para reafirmar a profissão docente como um fazer "desprofissionalizado" e os professores como transmissores de informações, ou seja, meros reprodutores de técnicas ou habilidades de determinada disciplina (ARROYO, 2002).
A lógica da formação instrumental centrase em um sistema que assegura a adaptação técnica e psicológica dos professores às exigências do mercado e à produção de qualificações novas para substituição das que se mostram obsoletas (CANÁRIO, 2003). Nesse processo, há uma perda da legibilidade do trabalho docente. Muitas vezes os professores não compreenderem o que estão fazendo no seu cotidiano escolar, principalmente porque aqueles que constroem os currículos baseados por competências são especialistas (administradores de alto padrão), enquanto os responsáveis por sua execução são os professores. Nessa visão mercadológica da escola, "na qual o ensino passa a ser visto apenas como uma parte de uma linha de produção" (VILLA, 1998, p. 52), os professores perdem o controle sobre o processo do seu próprio trabalho, o que contribui para a desqualificação desse profissional aos olhos da sociedade.

A formação continuada baseada no modelo de competência impacta diretamente na identidade do professor. Segundo Harvey (1989), este modelo é sustentado na dinâmica do descarte (das ideias, dos valores, dos relacionamentos estáveis, do apego às coisas e pessoas). Assim, o processo de trabalho e a formação dos professores se modificam e se tornam descartáveis constantemente.

Para Harvey (1989), a reestruturação do capital na modernidade "golpeou a experiência cotidiana do indivíduo" e afetou suas identidades. A fragmentação e a flexibilização do tempo, a supervalorização da competência, o deslocamento do processo de trabalho para os resultados do trabalho têm dificultado aos professores narrarem suas experiências, isto é, compreenderem-se na dimensão história. Assim, as identidades vão sendo apagadas e os professores tornando-se padronizados, como as mercadorias.

A perda da dimensão histórica do docente e de sua própria formação tem sido destacada como agravadora da dificuldade de engajamento dos professores na história de sua profissão. 
Ela é também prejudicial à conquista de uma perspectiva crítica sobre reformas educacionais e de defesa de opiniões próprias alicerçadas em conhecimentos sólidos (CIAMPI, 2015; MACCULLOCH, 2012).

Reforça essa perspectiva o viés tecnicista dos cursos de licenciatura, nos quais comumente teoria e prática estão apartadas. Endossam-se, assim, posturas autômatas, visões impressionistas e de alcance imediato, impedindo que as pessoas percebam que suas singularidades só adquirem sentido na articulação com uma experiência histórica mais ampla (GALZERANI, 2004).

A separação entre teoria e prática e o crescente tecnicismo têm reforçado os desenraizamentos espaço-temporais e o esfacelamento das relações sociais, mas não são prerrogativas do campo da educação. Elas são, antes, expressão de avanços da modernidade capitalista e, como tal, são ao mesmo tempo produto e instituidoras de sensibilidades modernas (BENJAMIN, 2006; GALZERANI, 2004). Portanto, a docência não pode prescindir de movimentos formativos que tematizem tempo, espaço e relações sociais nas quais as pessoas se inserem. No caso brasileiro, por exemplo, como compreender as políticas públicas que têm promovido o sucateamento da educação sem considerar a sua transformação em mercadoria?

A contrapelo das tendências prevalecentes nos cursos de formação que têm o intuito de capacitar e reciclar professores para atuarem em sala de aula, os dois projetos de pesquisa de formação docente não estavam voltados diretamente para os produtos a serem levados para a sala de aula, isto é, não havia a preocupação com a utilidade imediata do saber adquirido e o professor não fora visto como um meio de fazer chegar uma mensagem à sala de aula. 0 foco do trabalho foram os próprios professores, em sua pessoalidade ampla, ou seja, respeitado em suas dimensões racionais e sensíveis.

Nos primeiros meses do trabalho formativo, as questões feitas pelos professores - tais como: "de que maneira devemos trabalhar a Odisseia/a cidade com os alunos?" ou "como poderemos levar essa oficina para os alunos?" - evidenciavam sensibilidades educadas para olhar sempre para o outro, nunca para si mesmos. Evidenciavam também a urgência de ter um produto final a ser "aplicado" após terminar um processo de formação continuada. Assim, o desafio era construir com os professores uma formação a contrapelo dessas expectativas e modelos formativos hegemônicos.

Deveria ficar claro para os professores que aceitaram o convite de participar desses projetos que o fundamental era o fortalecimento de sua imagem de professor como sujeito da sua trajetória, capaz de produzir conhecimentos históricos e educacionais amalgamando diferente saberes relativos ao passado e ao presente, na relação com os desafios vividos na contemporaneidade. Tais propostas de formação enveredavam por brechas da modernidade para construir outros modos de relação com o tempo, com as memórias, de modo que fosse possível fortalecer a dimensão histórica e humana dos docentes, com vistas à construção de outras possibilidades de futuro.

Nesse sentido, os projetos formativos buscavam promover diálogos sobre as experiências vividas pelos professores em espaços escolares e não escolares, sendo a acepção de experiência docente mobilizada nessas pesquisas uma acepção alargada e não restrita à sala de aula (BENJAMIN, 1994; THOMPSON, 1981).

Miguel Arroyo (2002) reconhece que o ofício dos professores é mesclado ao trabalho, às situações em que vivem, à sua visão de mundo e de sociedade, à sua forma de agir, bem como a suas (in)certezas, como pessoas pertencentes a um grupo social e cultural. Portanto, há necessidade de considerar o que os professores pensam do e em seu cotidiano, de respeitar as suas diversidades de gênero e raça, bem como suas escolhas pedagógicas, partidárias e culturais, enfim, "o conjunto de seus valores, visão de mundo, de ser humano, de si mesmos, sua cultura" (ARROYO, 2002, p. 198). 
Nesse sentido, considerar as experiências vividas dos professores é base para processos formativos que vinculam sua proposta de produção de conhecimento à figura do professor, visto que as experiências permitem compreender os sentidos dos saberes produzidos do e no trabalho, e, ainda, os contextos em que os são elaborados, além de possibilitar a compreensão das relações que permeiam o fazer docente (THOMPSON, 1981).

Os referenciais teórico-metodológicos discutidos nos dois grupos de pesquisa ofereceram subsídios para questionar os modelos formativos em nosso país, na contemporaneidade, os quais procuram interditar a partilha das experiências, destruir as singularidades das culturais locais e desmoronar as percepções coletivas dos professores.

Considerando tais reflexões, os projetos formativos docente enveredaram pelas lentes da racionalidade estética (MATOS, 1989), um modo de conhecer comprometido com as experiências dos sujeitos e não com a regulação dos seus comportamentos. A racionalidade estética estimula a ampliação das visões de mundo dos sujeitos, incentivando o entrecruzamento de razão e sensibilidades. Nesse viés, a formação é percebida como um processo que liga as experiências do professor aos contextos sociais mais amplos.

Foram produzidos conhecimentos histórico -educacionais pelo viés coletivo, em uma relação dialogal e comprometida com as dimensões éticas, estéticas e responsivas (BAKTHIN, 2002, 2010) da prática docente, tendo o professor como protagonista e articulando suas experiências a práticas socioculturais mais amplas, para que ele se reconhecesse no contexto histórico com o qual interage.

\section{Percursos metodológicos}

Na perspectiva de formação docente adotada nessas duas pesquisas, o que se buscava estabelecer com cada grupo de professores que integrou os projetos era um trabalho de parceria, no qual se pudesse romper com a hierarquização dos saberes, promover um diálogo em que todos estivessem empenhados na busca de respostas para as questões levantadas ao longo do percurso formativo. Nessa trajetória foram se configurando duas pesquisas-ação.

São denominadas pesquisas-ação trabalhos que visam a mudanças na prática a partir de investigações ocorridas no local onde a prática se inscreve; que são protagonizados por sujeitos (e) pesquisadores ligados a tais práticas, numa relação de parceria; que têm caráter reflexivo e que seguem um ciclo de desenvolvimento no qual a continuidade e o aprimoramento da ação dependem da análise do percurso realizado. E, como a pesquisa-ação nasce de problemas detectados na prática, sua meta é a intervenção nesta prática de modo a solucionar ou minimizar o problema detectado pelos sujeitos (e) pesquisadores como aquilo que impulsiona tal pesquisa (FRANCO, 2005; GERALDI; FIORENTINI; PEREIRA, 1998).

Segundo a pesquisadora Maria Amélia Santoro Franco (2005, p. 487), "ao falarmos de pesquisa-ação, estaríamos pressupondo uma pesquisa de transforma-ção, participativa, caminhando para processos formativos". E para a pesquisadora Luiza Cortesão (2004, p. 2), “o que é mais relevante, mais característico da investigação-acção são questões do foro epistemológico, muito mais do que simples articulações metodológicas entre teoria e prática".

Para Maria Amélia Santoro Franco (2005, p. 488), em termos epistemológicos, a pesquisa -ação "pressupõe a integração dialética entre o sujeito e sua existência; entre fatos e valores; entre pensamento e ação; e entre pesquisador e pesquisado". Neste sentido, pesquisas-ação de caráter formativo-emancipatório não se limitam à racionalidade cognitivo-instrumental, pois, ao considerar "as relações humanas tecendo-se por meio de saberes intersubjetivamente partilhados, elas exigem dos sujeitos maior emprego da capacidade comunicativa" (FRANCO, 2005, p. 492). 
A pesquisa-ação de caráter formativo-emancipatório dilata a noção de sujeito no ato de produção de conhecimento, abarcando sua dimensão sensível, sem jamais desconsiderar sua dimensão racional. E reforça a necessidade desse sujeito, no caso o professor, conceber sua formação (profissional e cultural) engendrada historicamente (GALZERANI, 2004).

As pesquisas-ação desenvolvidas tinham certa peculiaridade, porque enfocavam o docente para além dos limites da sala de aula, abordando-o em um campo vasto de experiências, abarcando questões cotidianas de sua vida (GOODSON, 1995).

Em diálogo com a obra de Edward Palmer Thompson (1981, 1998, 2002), as experiências foram compreendidas como matéria de formação, historicamente situadas no tempo e no espaço, produtoras de culturas, na relação contraditória e ambivalente com "outras" práticas culturais localizadas historicamente. Uma vez que os sujeitos se constituem e são constituídos pelas experiências em diversas situações do cotidiano, desde os acontecimentos relacionados à família, ao lazer, ao trabalho, à igreja e a muitas outras possibilidades humanas (THOMPSON, 1981), as diversas experiências dos professores, vinculadas a uma dimensão de longa duração (desde os primórdios de vida do professor), são formadoras.

Edward Palmer Thompson (1981) tem inspirado muitos estudiosos do campo educacional a pensarem sobre a importância de considerar os professores como sujeitos que se constituem historicamente, em experiências atravessadas por movimentos de tensão/ distensão, nas fronteiras da resistência, dos conflitos e contradições.

As contribuições do filósofo Walter Benjamin (1994) também foram importantes para essas pesquisas-ação. Tanto Walter Benjamin (1994) quanto Edward Palmer Thompson (1981, 2002) apresentam suas aflições diante do distanciamento dos sujeitos das suas experiências, na modernidade, com o avanço do capitalismo. Ambos os autores percebem que a vida em sociedade se modificou radicalmente, as condições do viver urbano são frenéticas, a relação com o tempo ocorre a partir da sua dimensão econômica, impulsionando a ascensão de narrativas individuais de sujeitos isolados, que projetam sua vida para lutar pela sobrevivência e alcance do sucesso econômico.

Nessas pesquisas-ação, havia a preocupação de inserir o processo formativo dos docentes no tempo e no espaço, enraizando-o historicamente e refletindo sobre as experiências que o constituem no contexto da modernidade. A aproximação com a produção de Walter Benjamin favoreceu o delineamento teóricometodológico da pesquisa e reflexões sobre a articulação entre tempo e memória, sobre os sentidos do tempo na modernidade e sobre o lugar das memórias na produção de conhecimentos histórico-educacionais.

Benjamin (1994) afirma que, uma vez que o tempo se torna uma grandeza econômica, a disponibilidade de dar ouvidos ao outro diminui. A narrativa tradicional, que carregava as experiências comuns, não consegue transmiti-las mais, porque carece de quem as ouça e, depois, queira contar de novo, nelas agregando as marcas de sua própria experiência. Nesse tipo de narrativa a memória coletiva se formava com a contribuição de muitos narradores, cientes de sua finitude, portanto também cientes da necessidade de partilhar histórias. Com o declínio da arte de narrar, fortemente vinculada à transformação nos ritmos do trabalho coletivo, com o declínio dos espaços comuns e do tempo de ouvir, há também o declínio da memória compartilhada.

A memória dos romances, elaborados na solidão para serem lidos na solidão, contrasta com a breve memória do narrador, porque a memória do romancista é perpetuadora de histórias particulares, enquanto a memória compartilhada é consagrada a "muitos fatos difusos" (BENJAMIN, 1994, p. 211). Assim, "o espaço infinito da memória coletiva comum encolhe, dividindo-se em lembranças avulsas 
de histórias particulares" (GAGNEBIN, 2014, p. 221).

A memória dos romances tem sede de lembrança porque está prenhe de esquecimento, conforme Benjamin (1994) flagra na obra do escritor Marcel Proust. A dimensão voluntária da memória age numa atitude deliberada de não esquecimento, que chega com as explicações, como a informação, e que visa a preservar o passado. No entanto, ela se torna estéril para a experiência partilhada, porque não é nela que se fixam os elementos constitutivos do vivido, aqueles capazes de constituir as pessoas. Segundo Benjamin (1994), é na dimensão involuntária das memórias que se podem encontrar os dados que fixam a experiência vivida, guardados nos domínios do esquecimento e que afluem sem serem conscientemente solicitados. Assim, o esquecimento tem um papel constitutivo importante na formação das memórias.

Aquilo que se guarda profundamente concorre para formação dos hábitos, que frequentemente são transmitidos para outras gerações (como seiva ou como tradição). No movimento constante de rememorar, com as memórias voluntárias vêm junto fios de memórias involuntárias, que guardam a experiência nos esconderijos do esquecimento.

As memórias permitem ao sujeito que rememora ficar frente a frente com seus hábitos, com experiências que dão sentido à sua existência. 0 contato com as memórias voluntárias e involuntárias permite o estabelecimento de uma relação entre passado e presente com vistas a um futuro mais aberto, com certezas desestabilizadas.

Ao focalizar o tempo fragmentário da modernidade capitalista, Benjamin (1994) admite a pobreza de experiências, sem deixar de lançar uma centelha de esperança. Ele convida a construir com pouco, como faz no ensaio Experiência e Pobreza (BENJAMIN, 1994), escrito em 1933. Seu convite é para escovar a história a contrapelo, de modo a inventar outras formas de narração (nas ruínas da nar- rativa, uma transmissão entre os cacos de uma tradição em migalhas) na qual seja possível o intercâmbio das experiências. Ele apela para que se reinventem "outras formas de narração e memória, capazes de sustentar uma relação crítica com a transmissão do passado, com o lembrar e com a construção do futuro e o esperar" (GAGNEBIN, 2014, p. 221). Assim, faz-se necessário reconhecer a experiência que nasce dos conflitos, resistências, ambivalências, disputas de forças, bem como da diversidade do fazer humano, muitas vezes encontrado em perdas, ausências, destroços, ruínas, silêncios e esquecimentos.

Para colocar tal convite em ação num processo de produção de conhecimentos voltado à formação de professores, houve vários desafios. Um deles foi promover o intercâmbio do vivido, com tempo de qualidade para falar e ouvir. Ouvir o outro e a si mesmo. Outro desafio foi resistir ao apagamento das experiências e resistir ao distanciamento entre os sujeitos. Na urgência de fortalecer os professores enquanto pessoas, na relação com outras pessoas, singulares e inteiras, foram organizadas atividades de produção e partilha de narrativas com viés subjetivo, potencializadas pela rememoração.

Os professores que integraram ambas as pesquisas-ação responderam livremente a convites enviados às escolas públicas e, após esclarecimentos quanto aos procedimentos éticos adotados, assumiram pseudônimos a fim de preservarem suas identidades pessoais. Os grupos de professores passaram a se reunir periodicamente, em encontros organizados pelas professoras-pesquisadoras responsáveis por cada pesquisa-ação: professora Cyntia Simioni França (2015), responsável pelo projeto $O$ canto da Odisseia e as narrativas docentes: dois mundos que dialogam na produção de conhecimento histórico educacional, e Nara Rúbia de Carvalho Cunha (2016), responsável pela pesquisa Primaveras compartilhadas: (re) significando a docência na relação com cidade, memórias e linguagens. 


\section{0 canto da Odisseia e as}

\section{narrativas docentes: dois}

mundos que dialogam na produção de conhecimento histórico educacional

A pesquisa-ação $O$ canto da Odisseia e as narrativas docentes: dois mundos que dialogam na produção de conhecimento histórico educacional (FRANÇA, 2015) foi desenvolvida com professores que vivem na cidade de Londrina, localizada no interior do estado do Paraná. A cidade foi colonizada na primeira metade do século XX, sob a égide da modernidade e a promessa do progresso. Sua colonização não foi diferente dos ideários de outras cidades, tornadas metrópoles e tidas como símbolos do viver moderno. Vivencia-se em Londrina os avanços da modernidade, com as contradições, conflitos, tensões e desigualdades do sistema capitalista. Há uma intensa descaracterização do espaço urbano e o aceleramento do tempo (GIDDENS, 1991). E foi nesse ambiente, vivido também no cotidiano escolar, que os professores aceitaram o convite para participar do projeto, que ousava (re)inventar outras maneiras de se reapropriar do espaço dominado pelas técnicas de produção sociocultural, narrando as suas experiências vividas. Os professores protagonistas dessa pesquisa adotaram os seguintes pseudônimos: Minerva, Galateia, Alice, Saturnino, Sherazade, Tessália, Cleópatra e Ariadne.

Embora os professores pertencessem a diferentes escolas da região, desenvolveram-se encontros semanais na Escola Estadual Barão do Rio Branco, em Londrina, durante o ano de 2014, buscando produzir conhecimentos históricos educacionais no campo da formação docente em diálogo com experiências vividas. Entre as atividades desenvolvidas no projeto formativo com os professores, podem ser elencadas palestras, teatro, rodas de conversa, leituras de textos científicos, leitura da obra Odisseia, rememorações coletivas com fotogra- fias e objetos históricos sobre as histórias de vida de cada professor e produção de poesias e narrativas orais e escritas, potencializadas pela leitura da Odisseia.

A obra Odisseia, do autor Homero, datada do século VIII a.C., traduzida por Antônio Pinto de Carvalho, foi um importante documento histórico (THOMPSON, 1981) para potencializar a rememoração das experiências vividas dos professores. Ela narra experiências de Ulisses, herói grego que após a Guerra de Tróia sofre inúmeros infortúnios para retornar a Ítaca, sua terra natal. É uma narrativa sobre a jornada que ele vive de ilha em ilha pelo mesmo oceano, nas quais o herói se depara com cavernas, monstruosidades, figuras fantásticas, tentações e seduções marinhas até chegar ao palácio de Alcino, rei dos povos Feácios, conhecidos como excelentes marinheiros.

Durante a estadia nesse palácio, Ulisses participa de um banquete tipicamente grego que vai muito além de consumir os pratos servidos aos convidados. Trata-se de um ato de hospitalidade. Nesse banquete, o rei Alcino se despe da imagem de "anfitrião" do palácio ou "dono" da festa para não se sobrepor aos seus convidados e propiciar conforto, alegria e segurança. Alcino dá voz ao seu hóspede Ulisses, que se encontra emocionado durante a festa, ao ouvir o aedo Demódoco cantando as façanhas da Guerra de Tróia. Então, o rei Alcino pede ao seu convidado misterioso para contar a causa de tamanha emoção e Ulisses anuncia a todos os participantes do banquete que a história cantada pelo aedo é a sua própria história, revelando a sua identidade e os obstáculos que enfrentou até chegar lá.

O banquete grego é um momento para compartilhar as histórias de vida, as sabedorias e conhecimento. As experiências de um conviva, quando partilhadas em uma ceia, é o mais precioso presente que pode ser oferecido para o anfitrião da festa. Festa que é comandada por cada conviva, num intenso diálogo e emaranhado de histórias, entrecruzadas por narrativas compartilhadas. 
A obra Odisseia foi uma alegoria para potencializar as rememorações dos professores, que puderam durante os momentos de partilha atribuir outros sentidos às suas próprias experiências, como se percebe na leitura da narrativa produzida pelo professor que adotou o pseudônimo Saturnino. Há quatro anos ele é professor de História e trabalha em escolas públicas e privadas da cidade de Londrina.

\section{0 ato educativo e o fazer-se professor como banquete da (re)memória}

Em relação à educação, penso que o 'verdadeiro professor', tal qual o verdadeiro rei, é aquele que pratica sua atividade de educador como um anfitrião modelo da Odisseia: o próprio Ulisses ou mesmo o ilustre Alcino, que recebe os estrangeiros necessitados com humildade e hospitalidade. No banquete de Alcino, não é o anfitrião quem dá a voz na festa, mas sim o estrangeiro - ninguém mais que Ulisses, o herói da história e o próprio narrador de grande parte dela - uma vez que é convidado pelo dono do salão. Tocado pelo fabuloso dom do aedo Demódoco, Alcino convida o homem misterioso e necessitado que recebera em sua casa a compartilhar da causa de sua emoção. Convite que, de fato, dá início à narração das desventuras de Ulisses em sua jornada de retorno.

Segundo o exemplo de Alcino, talvez a função do professor não seja aquela de simplesmente tecer uma única narrativa, tarefa que poderia soar autoritária, impondo sentidos elementares ao aluno. Mas, sim, a de criar estratégias de comoção desse estrangeiro em relação à história (que é o aluno), convidando-o a tomar parte nesta narrativa, tornando-o protagonista da história e, dessa maneira, prezando pela conscientização da atitude de rememoração enquanto aquela que estabelece uma função significativa para o estudo dessa disciplina. Jornada difícil que exige o sacrifício daquele conforto promovido pela "caverna do ego" professor e do aluno.

A educação como um banquete! [...] 0 que está para ser oferecido como 'prato principal' nesses banquetes é, justamente, o diálogo, as narrativas entrecruzadas. Tanto do aluno que se faz um estrangeiro convidado, conhecendo uma cultura diferente, quanto do professor que assume, dentre os muitos pretendentes, o papel de anfitrião metamorfoseando-se ora em mendigo, ora em rei, ora brado navegante.......] De um jeito ou de outro, a educação nesse sentido me parece ser a rememoração de trajetórias de aprendizado. Não necessariamente a trajetória real de aprendizado do professor, mas seu declinar sobre ela, no processo de procurar por estratégias para 'ensinar' (ou dialogar) sobre a própria arte de aprender. Ao ensinar, o professor assume a tarefa de fiador de significados, mesmo que seja para desatá-los depois na humildade daquele que, a exemplo de Ulisses, permite a si mesmo ser um estrangeiro mendigando em seu próprio salão. [...] (SATURNINO, 2014, grifo do autor).

O projeto formativo trabalhou com as memórias de formação escolar, das vidas dos professores, de sua construção como cidadãos e do fazer-se professor, o que contribui significativamente para que a universidade os conheça e os respeite. A memória do professor Saturnino não foi um instrumento para dinamizar as práticas educativas; ela assumiu outra dimensão, pois trouxe as vozes dos sujeitos que se entrelaçam para construir leituras possíveis das suas experiências sociais, no tempo e no espaço. Nesse sentido, a memória não é "instrumento para a exploração do passado, é antes, o seu meio. A memória é onde se deu a vivência, assim como o solo é o meio no qual as antigas cidades estão soterradas" (BENJAMIN, 1994, p. 239).

Ao rememorar, o professor Saturnino deu outros sentidos para a docência. Na leitura de sua narrativa, alguns fios que a tecem podem ser puxados. Primeiro, a imagem de professor como um anfitrião, que se preocupa em recepcionar seus alunos em sala de aula e construir estratégias que os sensibilize a se enxergarem como sujeitos da e na história, por meio da rememoração de suas trajetórias de aprendizagens. Nesse sentido, a educação é compreendida como banquete, em que as narrativas entrecruzadas de alunos e professores são os pratos principais a serem saboreados. Nas relações dialógicas, promovidas em sala de aula, tal como acontece nos banquetes gregos, a 
figura do professor como exclusivo detentor do saber e o aluno como um simples receptor de uma única narrativa são rompidas, quebrando o círculo vicioso da hierarquização entre os sujeitos (alunos e professores).

Outro fio puxado dessa narrativa são as relações tensas e conflituosas do cotidiano escolar. 0 professor Saturnino reconhece que a relação dialógica de produção de conhecimento exige o declínio dos modos autoritários de se relacionar com o outro na escola e, também, pensar em como o festim pode ser organizado em sala de aula, ou seja, a "procura de estratégias para ensinar (dialogar) sobre a própria arte de aprender" (SATURNINO, 2014).

Outro fio a ser puxado é a imagem do professor como fiador de significados. 0 professor Saturnino coloca como desafio a necessidade de assumir uma postura humilde e de se deixar envolver com a alteridade, para se reconhecer no diálogo com o outro e se constituir nessa relação. A educação, para esse professor, é a rememoração de trajetórias de aprendizado das experiências de vida do aluno e do professor.

A narrativa do professor Saturnino possibilita-nos perceber o quanto a leitura da obra Odisseia foi potente e formativa. À medida que vieram à tona leituras plurais e inventivas dessa literatura, os professores puderam agir no tempo do agora, porque conseguiram reestabelecer vínculos com o presente, de modo a compreenderem problemas cotidianos de práticas culturais e escolares, individualistas, narcísicas, utilitárias, hierarquizadoras, excludentes, consolidadas com o avanço do capitalismo, a partir do final do século XIX.

A memória expressa em narrativas, nessa pesquisa-ação, instigou a transmissão de experiências entre diferentes gerações, "na relação do narrado com o vivido, na dimensão mais ampla de sujeito, de ser humano (portador de consciência e inconsciência), e, sobretudo, na recuperação da temporalidade" (GALZERANI, 2004, p. 296). É uma narrativa que não se aparta da memória e não existe sem as pontes entre passado, presente e futuro (BENJAMIN, 1994).
Primaveras compartilhadas: (re)significando a docência na relação com cidade, memórias e linguagens

A pesquisa-ação Primaveras compartilhadas: (re)significando a docência na relação com cidade, memórias e linguagens (CUNHA, 2016) foi desenvolvida com professores que moram e trabalham em Ouro Preto, município com pouco mais de 70 mil habitantes, cuja formação urbana inicial remonta a fins do século XVII e início do XVIII, no contexto do avanço dos movimentos de entradas e bandeiras rumo ao interior da antiga colônia portuguesa na América, em busca da captura de indígenas e de metais e pedras preciosas. Vila Rica, primeiro nome da cidade de Ouro Preto, foi a principal produtora de ouro para o Reino de Portugal, no período colonial da história do Brasil. A arquitetura urbana, marcada por suntuosas construções em estilo Barroco e Rococó, é reveladora do poder econômico de suas elites. Sua paisagem ainda guarda marcas da exploração de indígenas e africanos escravizados, ao mesmo tempo em que é possível encontrar manifestações da reelaboração cultural dos povos africanos em terras brasileiras após a diáspora.

Por ser uma das principais cidades históricas do Brasil - tombada como Monumento Nacional em 1933 e reconhecida Patrimônio Cultural da Humanidade em 1980, pela Unesco - é frequentemente palco e objeto de ações de educação patrimonial e de manifestações cívicas que se valem de diferentes práticas de memória, especialmente as comemorações e celebrações que mantêm tradições inventadas (HOBSBAWM; RANGER, 1997; RICOEUR, 2002). As escolas da região são convidadas a participarem dessas práticas, bem como são convidadas periodicamente a levarem alunos para prestigiar os eventos organizados pelas várias instituições museológicas presentes na cidade.

Dessa forma, a cidade compõe o universo das práticas dos professores, o que demanda 
pensá-la dentro dos percursos de formação docente. No entanto, a contrapelo das tendências comemorativas, que primam por focalizar a cidade como monumento nas atividades docentes, na pesquisa-ação B foi promovida uma investigação das relações cotidianas dos professores com a cidade. Considerou-se, a partir da crítica da cultura elaborada por Walter Benjamin (2006), a necessidade de refletir sobre os monumentos culturais inserindo-os no tempo e no espaço, compreendendo que sua forma de transmissão expressa uma concepção de história e relações sociais historicamente engendradas.

Para potencializar a proposta de estudo das relações com a cidade e as sensibilidades urbanas, estabeleceu-se uma parceria com o Museu Casa Guignard, instituição vinculada à Superintendência de Museus e Artes Visuais da Secretaria de Cultura do Estado de Minas Gerais. Ele foi aberto em Ouro Preto, em 1987, numa iniciativa da Fundação Guignard, dedicada à valorização da obra e memória de Alberto da Veiga Guignard, um dos principais pintores modernistas do Brasil. Os últimos anos de sua vida foram vividos em Minas Gerais e ele nutria uma profunda admiração pela cidade de Ouro Preto, retratada em muitas de suas obras, especialmente do gênero paisagem.

De acordo com a pesquisadora Taisa Helena Pascale Palhares (2010), a paisagem nas obras de Guignard é mais do que um gênero pictórico, ela é tratada como um problema moderno. Há uma ambiguidade entre interioridade e mundo exterior em Guignard, em cujas obras a paisagem se reveste também dos olhos de quem a vê.

Seguindo passos de Guignard, a tensão entre paisagem e observador foi mote de reflexão para os professores do Primaveras Compartilhadas, assim como é dentro da ação educativa do Museu Casa Guignard.

Os professores protagonistas dessa pesquisa-ação escolheram como pseudônimos nomes de flores: Cattleya, Maria-sem-Vergonha, Flor de Lótus, Margarida, Orquídea e Girassol. 0 grupo se reuniu quinzenalmente ao longo de um ano, entre maio de 2012 e maio de 2013, no Museu Casa Guignard. E de lá partia em incursões pela cidade para observações da paisagem, piqueniques em parques públicos $\mathrm{e}$ adros de igrejas, visitas a museus e exposições. $\mathrm{Na}$ interação com a paisagem urbana foram promovidas diversas oficinas de arte, como desenho, fotografia e frottage. Para expandir o campo de reflexão sobre cidade, foram promovidas leituras de textos científicos e literários e rodas de conversa com pesquisadores dedicados à temática urbana, vindos de outras cidades e realidades urbanas. Em maio de 2013, os professores organizaram uma exposição coletiva de seus trabalhos no Salão Principal da Casa dos Contos de Ouro Preto, um dos principais espaços de exposição da cidade.

Em todos os encontros havia o momento da partilha de experiências, através de rememorações coletivas e narrativas de cunho subjetivo e memorial sobre experiências urbanas vividas pelos professores. Grande parte das narrativas foi entregue livremente pelos professores para compor o acervo documental da pesquisa. A seguir, o leitor poderá entrar em contato com uma delas:

\section{Flashes... cheiros... gostos... sons... saudades}

Quando a cidade me toca ou como sou tocada pela cidade? Pergunta capciosa essa, não? A mente divaga... Mas as imagens surgem e acumulam-se, formam-se quadros, flashes... cheiros... gostos... sons... saudades!!

Manhã com brumas em Ouro Preto, este quadro, pintura cinza com raios dourados apolíneos, toca-me com leveza e fresca trazendo esperança, paz.

A imagem da minha mãe na casa velha do Antônio Dias em sua velha cozinha, o 'cuador' de pano e o cheiro de café recém-feito. Assim, a cidade toca-me.

Manhã de brumas meu velho pai descendo a ladeira de Santa Efigênia, cantando 'Boemia', toca-me. 
Festa de Santa Efigênia, sinos festivos anunciando a princesa Núbia, toca-me e me acaricia, torno-me novamente criança nos braços carinhosos de minha vó [...].

Sinos da Matriz de Nossa Senhora da Conceição nos domingos pela manhã, como anjos anunciando Maria a nos cobrir com seu manto azul-estrela, toca-me.

Tocar, ser tocado ou tocarmo-nos? Sigo assim, sendo tocada e tocando na maioria das vezes sem perceber que esse ato é contínuo em minha vida (um eterno ir e vir como um rosário de bênçãos onde cada conta representa sons, perfumes, gestos, saudades!). (FLOR DE LÓTUS, 2013).

Nesse movimento de partilha e de escuta das palavras do outro, o projeto formativo foi se configurando como percurso de questionamento de sensibilidades que imputam rótulos à cidade e aos professores.

Nessa narrativa de memórias é possível flagrar a constituição do sujeito na relação estreita com a cidade, tanto em seus aspectos materiais quanto imateriais. 0 sujeito que rememora expressa a cidade da forma como a capta, por meio de seus sentidos, permitindo ao leitor observar a sedimentação nas sensibilidades de Flor de Lótus de experiências vividas no espaço urbano. A memória, embora fragmentária e fugidia, pintou uma tela com clima, sabores, sons, paisagens e costumes, entremeados por construções arquitetônicas, instituições e manifestações culturais. A memória trouxe uma cidade plural, marcante não apenas por sua relevância histórica e monumental, mas, sobretudo, pelas relações pessoais e sociais estabelecidas nesse ambiente.

Flor de Lótus traz em primeiro plano a cidade como objeto de contemplação e encantamento, expressando uma construção social de sua imagem como monumento. Tal sensibilidade é componente da visão de quem rememora. No entanto, o espaço recortado não é o mais registrado em cartões postais. A narrativa desvia o foco da contemplação para locais marginalizados em detrimento daqueles considerados mais expressivos para a história e memórias dominantes. Mesclam-se fios de experiências outras, amálgamas de experiências formativas na relação com diversas culturas locais e que extrapolam as imagens prevalecentes da cidade nos livros didáticos e nas diversas mídias.

Adentrando detalhes do quadro delineado por Flor de Lótus, rompe-se com o olhar de contemplação. Vê-se a cidade como meio de interação entre pessoas da família e da comunidade, de constituição de sujeitos que dão vida aos costumes locais e a eles conferem dinamicidade. Ao frisar na grafia a palavra "cuador", ao invés de coador, Flor de Lótus, professora de Língua Portuguesa, destaca uma variante linguística do Português, marcando a singularidade da fala do mineiro e se reconhecendo nela. Essa singularidade também compõe suas sensibilidades, assim como o ritmo de atividades cotidianas marcado pelo toque dos sinos das igrejas, que significam na história da cidade espaços de socialização e segregação social. Santa Efigênia, reconhecida como protetora dos afrodescendentes em Ouro Preto, está presente nessa narrativa em uma cena de aconchego, na qual se reconhece um abrigo, um lugar na comunidade, um ponto de referência.

No movimento de rememoração, a cidade se revela constitutiva de experiências individuais, em diálogo com visões coletivas ou constituídas no coletivo. Enquanto método dialético de conhecimento, a rememoração é uma ação deliberada de trazer o outro à tona, numa busca incessante. Ela assume uma função política ligada ao tempo do agora ou da agorabilidade: "acordar os mortos e juntar os fragmentos" (BENJAMIN, 1994, p. 226). As trazer os fios de experiências que muitas vezes são relegadas ao esquecimento ou à marginalidade, as memórias convidam ao enfrentamento de questões negligenciadas ou que se pretende encarcerar no passado, sem que tenham sido resolvidas. A Ouro Preto monumental não se sobressai nesse movimento reflexivo, mas a cidade das múltiplas culturas, das relações conflituosas e das resistências, a cidade vivida e sentida na experiência cotidiana dos moradores/professores. 
A narrativa de Flor de Lótus não é um resgate do vivido. Há um intervalo de tempo entre o passado e o presente, que age sobre as sensibilidades do sujeito que rememora. A narrativa reafirma o que está latente, compondo experiências individuais e coletivas. É sobre elas e a partir delas que o professor repensa a si mesmo nesse espaço e, possivelmente, reelabora sua prática.

\section{Considerações finais}

As duas pesquisas desenvolvidas constituem propostas de formação docente peculiar, desvinculadas diretamente do ambiente escolar e da figura docente na escola. Ambas defendem uma proposta metodológica de trabalho coletivo, envolvendo razão e sensibilidades, que reforça a compreensão do sujeito em diálogo com o outro (inclusive seus próprios outros) e favorece o desenvolvimento de uma reflexão implicada no, pelo e para o social, que seja capaz de contribuir com os posicionamentos éticos e responsivos nos processos formativos e educativos.

0 trabalho com narrativas, nesses processos de produção de conhecimento histórico educacional, proporcionou um desvio pelos diversos (des)caminhos da linguagem, tomando-a como expressão da relação sensível com o mundo e como meio de (trans)formação dos sujeitos e, quiçá, (trans)formação do meio social em que estão inseridos.

As narrativas dos professores foram potencializadas pelas práticas de rememorações coletivas, tendo como medium de reflexão uma obra literária e uma cidade. E em ambos os caminhos, o que se destacou foram as relações sociais constituídas no tempo e no espaço. A partir desse movimento de rememorar e narrar suas próprias experiências, entrelaçadas em outras experiências, em diferentes tempos e espaços, os professores foram percebendo sua própria formação não apenas como docentes, mas como pessoas pertencentes a uma comunidade, imersas em culturas historicamente engendradas. 0 singular foi visto como imbricado em diferentes dimensões do humano e do social, não determinado a priori, mas resultante das relações dialógicas/conflituosas e das resistências dos sujeitos.

Houve dificuldades em relação a atitudes utilitaristas e visões imediatistas, comuns nas sensibilidades de pessoas em processos de formação, que muitas vezes dificultavam a troca de experiências. Aos poucos, coletivamente essas visões foram sendo movimentadas e deslocadas. Foram partilhados sonhos de mudanças no presente. E isso é algo que vai muito além da informação ou do acúmulo de conhecimentos acerca de métodos e técnicas de desenvolvimento de competências e habilidades para sobreviver no mercado de trabalho, porque coloca em pauta os sentidos do fazer docente e das escolhas ou adesões dos professores.

Essas pesquisas reafirmaram o trabalho de formação docente em diálogo com as experiências, por meio de produção e partilha de narrativas e de rememorações coletivas, como um ato político que visa à transformação do presente, como busca de um porvir mais significativo para os sujeitos e de uma transformação pelo conhecimento, na relação com o outro, comprometida com um projeto humano emancipatório.

\section{REFERÊNCIAS}

ARROIO, Miguel G. Ofício do mestre: imagens e autoimagens. 5. ed. Petrópolis, RJ: Vozes, 2002.

BAKTHIN, M. Estética da criação verbal. São Paulo: Martins Fontes, 2002.

BAKTHIN, M. Para uma filosofia do ato responsável. São Carlos, SP: Pedro \& João Editores, 2010.

BARBIER, René. A pesquisa-ação. Tradução de Lucie Didio. Brasília, DF: Liber Livro, 2007.

BENJAMIN, Walter. Magia e técnica, arte e política: ensaios sobre literatura e história da cultura. Tradução de Sérgio Paulo Rouanet. 7. ed. São Paulo: Brasiliense, 1994.

BENJAMIN, Walter. Passagens. Tradução de Irene Aron e Cleonice Paes Barreto Mourão. São Paulo: 
Imprensa Oficial do Estado, 2006.

BENJAMIN, Walter. Rua de mão única. Tradução de Rubens Rodrigues Torres Filho e José Carlos Martins Barbosa. 5. ed. São Paulo: Brasiliense, 1985.

CANÁRIO, Rui. Formação e situações de trabalho. Porto: Porto, 2003.

CIAMPI, Helenice. O presente do passado na formação do professor de História. Revista Territórios \& Fronteiras, v. 8, n. 1, p. 113-130, jan./ jun. 2015.

CORTESÃO, Luíza. Investigação-Acção - um convite a práticas cientificamente transgressivas. Recife, 2004. Texto de conferência promovida pelo Centro Paulo Freire- estudos e pesquisa.

CUNHA, Nara Rúbia de Carvalho. Primaveras compartilhadas: (re)significando a docência na relação com cidade, memórias e linguagens. 2016. 250f. Tese (Doutorado em Educação) - Faculdade de Educação, Universidade Estadual de Campinas (UNICAMP), Campinas, SP, 2016.

ELLIOTT, John. Recolocando a pesquisa-ação em seu lugar original e próprio. In: GERALDI, Corinta Maria Grisolia; FIORENTINI, Dario; PEREIRA, Elisabete Monteiro de Aguiar (org.). Cartografias do trabalho docente: professor(a)pesquisador(a). Campinas, SP: Mercado das Letras, 1998. p. 137152.

FRANCO, Maria Amélia Santoro. Pedagogia da pesquisa-ação. Educação e Pesquisa, São Paulo, v. 31, n. 3, p. 483-502, set./dez. 2005.

FRANÇA, Cyntia Simioni. 0 canto da Odisseia e as narrativas docentes: dois mundos que dialogam na produção de conhecimento históricoeducacional. 2015. 346f. Tese (Doutorado em Educação) - Faculdade de Educação, Universidade Estadual de Campinas (UNICAMP), Campinas, SP, 2015.

GAGNEBIN, Jeanne-Marie. Limiar, aura e rememoração: ensaios sobre Walter Benjamin. São Paulo: Editora 34, 2014.

GALZERANI, Maria Carolina B. Memória, história e (re)invenção educacional: uma tessitura coletiva na escola pública. In: MENEZES, Maria Cristina (org.). Educação, memória e história. Campinas, SP: Mercado das Letras, 2004. p. 287-330.

GAY, Peter. A experiência burguesa: da Rainha Vitória a Freud - a educação dos sentidos. São Paulo: Cia das Letras, 1988.

GERALDI, Corinta Maria Grisolia; FIORENTINI,
Dario; PEREIRA, Elisabete Monteiro de Aguiar (org.). Cartografias do trabalho docente: professor(a)pesquisador(a). Campinas: Mercado das Letras, 1998.

GIDDENS, Anthony. As consequências da modernidade. São Paulo: EdUNESP, 1991.

GOODSON, I. Dar voz ao professor: histórias de vida dos professores e o seu desenvolvimento profissional. In: NOVOA, A. (org.). Vidas de professores. 2. ed. Porto: Porto Editora, 1995. p. 63-78.

HARVEY, David. A condição pós-moderna - uma pesquisa sobre as origens da mudança social. São Paulo: Loyola, 1989.

HOBSBAWM, Eric; RANGER, Terence (org.). A invenção das tradições. Rio de Janeiro: Paz e Terra, 1997.

LIMA, Maria Emília Caixeta de Castro; GERALDI, Corinta Maria Grisolia; GERALDI, João Wanderley. 0 trabalho com narrativas na investigação em educação. Educação em Revista, Belo Horizonte, v. 31, n. 1, p. 17-44, mar. 2015.

MACCULLOCH, Gary. História da educação e formação de professores. Revista Brasileira de História, v. 17, n. 49, p. 121-238, jan./abr. 2012.

MATOS, Olgária. Os arcanos do inteiramente outro. São Paulo: Brasiliense, 1989.

PALHARES, Taisa Helena Pascale. Modernidade, tradição e caráter nacional na obra de Alberto da Veiga Guignard. 2010. 128f. Tese (Doutorado em Filosofia) - Faculdade de Filosofia, Letras e Ciências Humanas, Universidade de São Paulo (USP), São Paulo, 2010.

PRADO, G. V. T. Narrativa e pesquisa em uma tríplice perspectiva: singularidade e acontecimento ético nos processos investigativos. In: ABRAHÃO, Maria Helena Menna Barreto; BRAGANÇA, Inês Ferreira de Souza; ARAÚJO, Mairce da Silva (org.). Pesquisa (auto)biogrática, fontes e questões. Vol 1. Curitiba: CRV, 2014. p. 215-230.

PRADO, G. V. T. et al (org.). Metodologia narrativa de pesquisa em educação: uma perspectiva bakhtiniana. São Carlos, SP: Pedro\&João Editores, 2015.

RICOEUR, Paul. A memória, a história, o esquecimento. Campinas, SP: Editora da Unicamp, 2002.

THOMPSON, Edward Palmer. A miséria da teoria ou um planetário de erros. Rio de Janeiro: Zahar, 1981. 
THOMPSON, Edward Palmer. Costumes em comum: estudos sobre a cultura popular tradicional. São Paulo: Companhia das Letras, 1998.

THOMPSON, Edward Palmer. Os românticos: a
Inglaterra na era revolucionária. Rio de Janeiro: Civilização Brasileira, 2002.

VILLA, Fernando G. Crise do professorado: uma análise crítica. Campinas, SP: Papirus, 1998.

Recebido em: 02/01/2020

Aprovado em: 23/02/2020 